\title{
Surgical Outcomes, Health Care Utilization, and Costs Associated with Staple Line Buttressing Among Primary Sleeve Gastrectomy Patients
}

\author{
Sanjoy Roy ${ }^{1} \cdot$ Yuexi Wang $^{2}$ [D $\cdot$ Rajesh Mallampati $^{2} \cdot$ Stephen Johnston ${ }^{1}$
}

Received: 20 April 2020 / Revised: 7 August 2020 / Accepted: 10 August 2020 / Published online: 10 September 2020

(C) The Author(s) 2020

\begin{abstract}
Purpose Staple line buttressing is a method of reinforcing surgical staple lines using buttress materials. This study evaluated surgical outcomes, hospital utilization, and hospital costs associated with staple line buttressing among patients who underwent primary laparoscopic sleeve gastrectomy (PLSG) in the United States.

Methods This was a retrospective cohort study using Premier Healthcare Database data from January 1, 2012 to December 31, 2017. Patients aged $\geq 18$ years who underwent PLSG were selected and assigned to buttress or non-buttress cohorts based on the use of buttress material during their hospitalization for PLSG (index). Propensity score matching (PSM) was conducted to balance patient demographic and clinical characteristics between the cohorts. Generalized estimating equation models were used to compare the clinical and economic outcomes of the matched buttress and non-buttress users during the index hospitalization. Results A total of 38,231 buttress and 27,349 non-buttress patients were included in the study. After PSM, 24,049 patients were retained in each cohort. Compared with non-buttress cohort, the buttress cohort patients had a similar rate of in-hospital leaks $(0.28 \%$ vs $0.39 \% ; p=0.160)$ and a lower rate of bleeding $(1.37 \%$ vs $1.80 \%, p=0.015)$, transfusion $(0.56 \%$ vs $0.77 \%, p=0.050)$, and composite bleeding/transfusion ( $1.57 \%$ vs $2.04 \%, p=0.019)$. Total costs $(\$ 12,201$ vs $\$ 10,986, p<0.001)$ and supply costs ( $\$ 5366$ vs $\$ 4320, p<0.001$ ) were higher in the buttress cohort compared with the non-buttress cohort.

Conclusions Staple line buttressing was associated with an improvement in complication rates for bleeding and transfusion. Total and supply costs were higher in the buttress cohort, necessitating further research into cost-effective buttressing materials.
\end{abstract}

Keywords Staple line buttress $\cdot$ Laparoscopic sleeve gastrectomy $\cdot$ Surgical outcome $\cdot$ Health care costs

\section{Introduction}

Obesity is an increasingly prevalent problem in the United States [1]. Laparoscopic sleeve gastrectomy (LSG) is widely recognized as a primary bariatric procedure for treating patients who are obese, with or without select medical conditions $[2,3]$. LSG is proven to be an effective procedure with many

Electronic supplementary material The online version of this article (https://doi.org/10.1007/s11695-020-04917-2) contains supplementary material, which is available to authorized users.

Yuexi Wang

ywang@statinmed.com

1 Johnson \& Johnson, Inc., New Brunswick, NJ, USA

2 STATinMED Research, Ann Arbor, MI, USA advantages; however, complications such as bleeding, staple line leaks, and abscess formation may occur $[4,5]$.

Staple line buttressing is a method of reinforcing surgical staple lines using buttress materials in bariatric surgical procedures [6, 7]. Buttress materials are broadly classified as absorbable, semi-absorbable, and non-absorbable [8]. Absorbable buttresses are especially advantageous as they do not leave a permanent foreign object in a patient's body, potentially reducing post-surgical complications [8].

Buttressing the staple line of LSGs is known to provide favorable outcomes in terms of surgical complications and health care utilization. Evidence from existing studies shows a reduction in bleeding, overall complications, and other adverse events associated with the use of buttressing in LSG [6, 7, 9-11]. One study that examined patients undergoing LSG in the Metabolic and Bariatric Surgery Accreditation and Quality Improvement Program found that patients with buttressing had a $30 \%$ lower rate of postoperative bleeding 
[10]. In another meta-analysis, there was a non-statistically significant reduction in postoperative leaks associated with buttress use among patients who underwent LSG [11]. Buttress use has also been associated with shorter operative times, shorter hospitalization length of stay (LOS), and fewer morbidities $[6,12]$. These advantages could outweigh any additional costs incurred from buttress use.

While study outcomes associated with staple line buttressing have been evaluated in randomized clinical trials (RCTs) and prospective cohort studies with small sample sizes, there is a lack of recent real-world evidence among patients undergoing LSG in the United States. Utilizing a large nationwide healthcare database, this study sought to examine the associations of buttress use with surgical outcomes, hospital utilization, and hospital costs among patients who underwent a primary LSG.

\section{Methods}

\section{Data Source}

This was a retrospective cohort study using Premier Healthcare Database (PHD) data from January 1, 2012 through December 31, 2017 [13]. PHD is a large, service-level, all-payer US hospital database that contains information on inpatient discharges, primarily from geographically diverse non-profit, non-governmental, and community/teaching hospitals and health systems from rural and urban areas. It contains $>970$ contributing hospitals located throughout the country and includes information on hospital and visit characteristics as well as patient data from standard hospital discharge billing files. The database contains data from $>208$ million unique patients and $>2.5$ million daily service records for an average of $>5$ million deidentified hospital discharges per year. Multiple health care encounters can be tracked within a hospital for any patient. The database contains deidentified patient information, is Health Insurance Portability and Accountability Act (HIPAA) compliant, and is considered exempt from institutional review board (IRB) approval [14]. The database has been used previously to evaluate surgical outcomes $[15,16]$. A commercially available data license is required for access to the database and may be obtained by contacting the Premier Healthcare Database directly.

\section{Patient Selection}

Patients with evidence of hospital discharge records including International Classification of Diseases, Ninth Revision, Clinical Modification (ICD-9-CM) and ICD Tenth Revision, Procedure Coding System (ICD-10-PCS) procedure codes for LSG surgery (ICD-9-CM: 43.82; ICD-10-PCS: 0DB64Z3) during the study identification period (April 1, 2012 to September 30,2017) were selected. The first observed inpatient visit with evidence of the procedure was designated as the index hospitalization. Patients were required to be aged $\geq$ 18 years on the year of index hospitalization. Patients with LSG as a secondary procedure and those with LSG any time prior to their index hospitalization were excluded. Patients were also excluded if they had a non-elective admission for the index hospitalization or did not have obesity as their primary diagnosis. Finally, patients whose procedure was converted to an open procedure during the index hospitalization and those with band removal/revisions during the baseline period or index hospitalizations were excluded as well.

The final study sample was assigned to two cohorts based on evidence of buttress use ascertained from hospital chargemaster records. Patients with evidence of buttress use (both absorbable and non-absorbable) during the index hospitalization were assigned to the buttress cohort; all patients without evidence of buttress use, including those who could have undergone over-sewing during the index hospitalization, were assigned to the non-buttress cohort. All analyses were exclusively restricted to patients undergoing LSG as a primary procedure (primary, secondary, and revisional procedures excluded) conducted in hospitals for which there was at least one record of buttress use during the same year to avoid misclassification from hospitals that may use buttressing but fail to record it in their chargemaster records.

\section{Baseline Characteristics}

Patient demographics including age, sex, race, geographic region, marital status, and payer type during the index hospitalization were examined. Each patient's body mass index (BMI) and Charlson comorbidity index (CCI) score during the baseline period (during index hospitalization and the 3 months prior) and their year of surgery were recorded. Patient hospital characteristics included for analysis were procedure volume, hospital type (teaching/non-teaching), hospital location (urban/rural), and bed size $(<200,200-499$, or $\geq 500$ beds $)$. Procedure volume was defined as the hospital's frequency of LSG procedures during the year of index hospitalization.

\section{Outcome Measures}

Surgical outcomes, healthcare utilization, and costs during the index hospitalization were measured and compared between buttress and non-buttress cohorts. Surgical outcomes included in-hospital leaks, bleeding, and transfusion, identified by ICD9/10-CM/PCS codes. A composite bleeding/transfusion outcome representing bleeding and/or transfusion events was also included. Healthcare utilization included LOS (in days) and time in the operating room (OR, in hours). Total hospital costs and those specifically related to the OR, room and board, and supplies during the index hospitalization were calculated and adjusted to 2017 US dollars; costs were measured from the hospital perspective as opposed to the payer perspective. 
Patients with ICD-9-CM and ICD-10-PCS procedure codes for laparoscopic sleeve gastrectomy during identification period (April 2012-September 2017); first observed inpatient visit was designated as the index hospital visit

$$
\mathrm{N}=125,162
$$

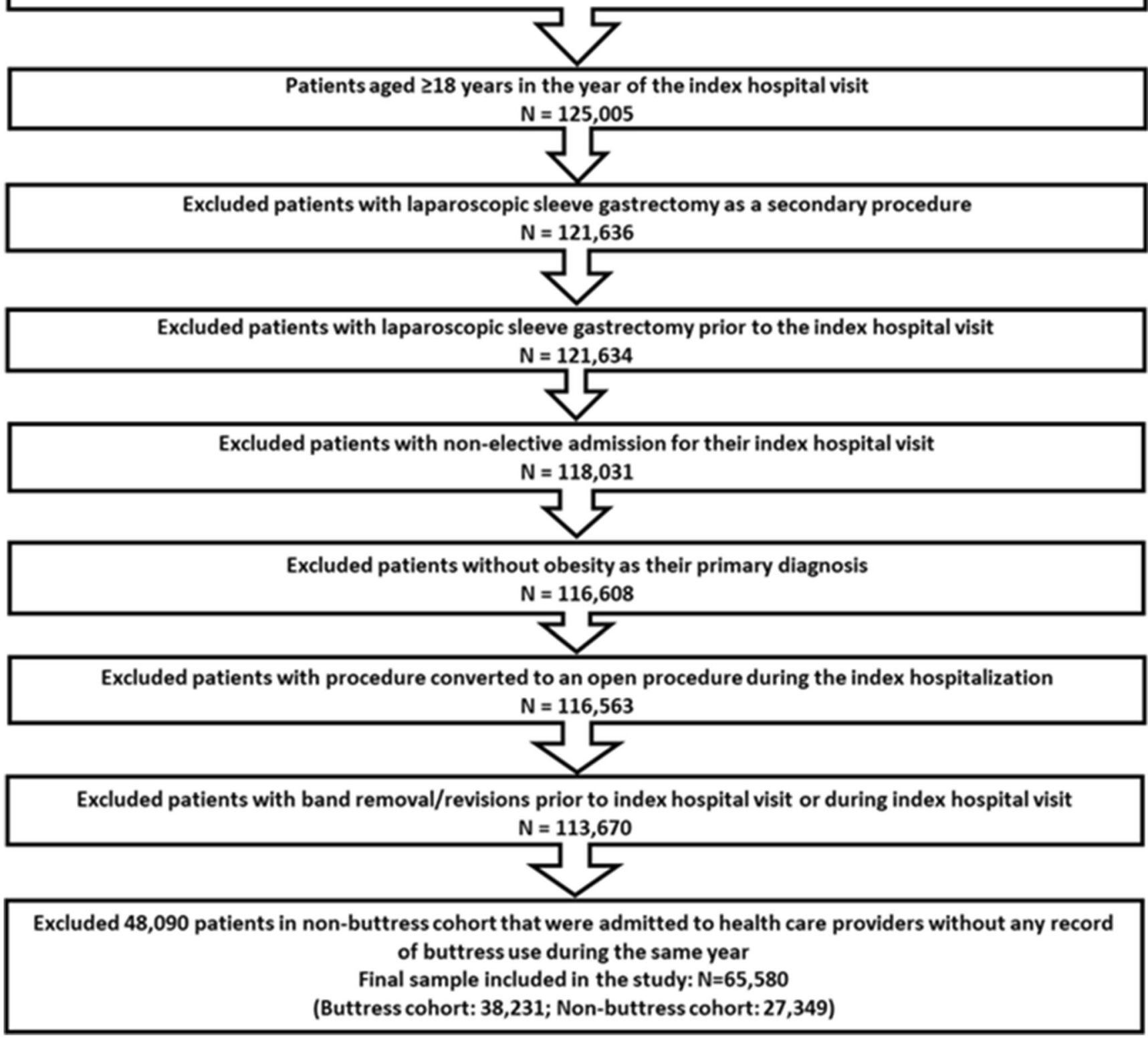

Fig. 1 Patient selection criteria. ICD-9-CM: international classification of diseases, ninth revision, clinical modification; ICD-10-PCS: international classification of disease, tenth revision, procedure coding system

\section{Statistical Methods}

\section{Descriptive Analysis}

Descriptive statistics were used to compare means and proportions between the buttress and non-buttress cohorts for baseline characteristics and outcome measures before propensity score matching (PSM). Standardized mean differences (SMDs) between these cohorts were calculated as 100 times the absolute value of the SMD; as per standard practice, an SMD > 10 was considered to be indicative of imbalance between cohorts [17].
PSM was used to perform a 1:1 match between study cohorts with respect to all hospital and patient characteristics described above, with a maximum caliper width of 0.01 for the absolute probability using the nearest neighbor technique without replacement. Generalized estimating equation (GEE) models, accounting for hospital-level clustering of the study outcomes, were used to compare surgical outcomes and economic outcomes between the matched buttress and non-buttress cohorts. Surgical outcomes were modeled using a binomial distribution with a logit link; LOS and OR time were modeled using negative binomial distribution, and cost outcomes were modeled using a gamma 
Table 1 Demographic characteristics before propensity score matching

\begin{tabular}{|c|c|c|c|c|c|}
\hline \multirow[t]{3}{*}{ Baseline variables } & \multirow{2}{*}{\multicolumn{2}{|c|}{$\frac{\text { Non-buttress cohort }}{(N=27,349)}$}} & \multirow{2}{*}{\multicolumn{2}{|c|}{$\frac{\text { Buttress cohort }}{(N=38,231)}$}} & \multirow[t]{3}{*}{ SMD } \\
\hline & & & & & \\
\hline & $N /$ mean & $\% / \mathrm{SD}$ & $N /$ mean & $\% / \mathrm{SD}$ & \\
\hline Age & 44 & 11.8 & 44.6 & 11.9 & 5 \\
\hline $18-34$ & 6329 & $23.1 \%$ & 8296 & $21.7 \%$ & 3.5 \\
\hline $35-54$ & 15,490 & $56.6 \%$ & 21,393 & $56.0 \%$ & 1.4 \\
\hline $55-64$ & 4069 & $14.9 \%$ & 6395 & $16.7 \%$ & 5.1 \\
\hline $65+$ & 1461 & $5.3 \%$ & 2147 & $5.6 \%$ & 1.2 \\
\hline \multicolumn{6}{|l|}{ Race } \\
\hline African American & 5711 & $20.9 \%$ & 6318 & $16.5 \%$ & 11.2 \\
\hline Caucasian & 17,893 & $65.4 \%$ & 27,011 & $70.7 \%$ & 11.2 \\
\hline Other race & 3389 & $12.4 \%$ & 4667 & $12.2 \%$ & 0.6 \\
\hline Unknown race & 356 & $1.3 \%$ & 235 & $0.6 \%$ & 7.1 \\
\hline \multicolumn{6}{|l|}{ Sex } \\
\hline Male & 5820 & $21.3 \%$ & 7955 & $20.8 \%$ & 1.2 \\
\hline Female & 21,529 & $78.7 \%$ & 30,276 & $79.2 \%$ & 1.2 \\
\hline \multicolumn{6}{|l|}{ Marital status } \\
\hline Married & 13,996 & $51.2 \%$ & 20,441 & $53.5 \%$ & 4.6 \\
\hline Single & 11,234 & $41.1 \%$ & 15,193 & $39.7 \%$ & 2.7 \\
\hline Other & 2119 & $7.7 \%$ & 2597 & $6.8 \%$ & 3.7 \\
\hline \multicolumn{6}{|l|}{ US geographic region } \\
\hline Northeast & 5415 & $19.8 \%$ & 8200 & $21.4 \%$ & 4.1 \\
\hline Midwest & 5691 & $20.8 \%$ & 7252 & $19.0 \%$ & 4.6 \\
\hline South & 13,319 & $48.7 \%$ & 17,826 & $46.6 \%$ & 4.2 \\
\hline West & 2924 & $10.7 \%$ & 4953 & $13.0 \%$ & 7 \\
\hline \multicolumn{6}{|l|}{ Payer type } \\
\hline Managed care and commercial & 17,842 & $65.2 \%$ & 24,716 & $64.6 \%$ & 1.2 \\
\hline $\begin{array}{l}\text { Government (Medicare, Medicaid) and other } \\
\text { government payers }\end{array}$ & 7607 & $27.8 \%$ & 10,540 & $27.6 \%$ & 0.5 \\
\hline $\begin{array}{l}\text { Other (i.e., self-pay, workers' compensation, } \\
\text { direct employer contract, other) }\end{array}$ & 1877 & $6.9 \%$ & 2968 & $7.8 \%$ & 3.5 \\
\hline Indigent and charity & 23 & $0.1 \%$ & 7 & $0.0 \%$ & 2.9 \\
\hline
\end{tabular}

$S D$ standard deviation, $S M D$ standardized mean difference

Italics $=$ Significant difference between the study cohorts if SMD $>10$ distribution with log link. Marginal effects were computed using the recycled prediction method [18]. A $p$ value of $<0.05$ was set as the threshold for statistical significance. All statistical analyses were conducted using the Statistical Analysis System (SAS) v.9.4. (Cary, North Carolina, USA).

\section{Results}

\section{Patient and Hospital Characteristics}

After applying selection criteria, 38,231 patients with buttress use and 27,349 patients without buttress use were included in the study (Fig. 1).
Before matching, patients in the buttress cohort had similar age (45 vs 44 years), sex (male: $20.8 \%$ vs $21.3 \%$ ), marital status (married: $53.5 \%$ vs $51.2 \%$ ), and geographic region compared with non-buttress cohort patients. Managed care and commercial plans (64.6\% vs $65.2 \%$ ) accounted for the highest proportion of payers followed by governmental plans (27.6\% vs 27.8\%). The proportion of Caucasian patients was slightly higher in the buttress cohort $(70.7 \%$ vs $65.4 \%$; SMD = 11.2), while the proportion of African American patients was slightly higher in the non-buttress cohort (20.9\% vs $16.5 \%$; SMD $=11.2)($ Table 1$)$.

Similar CCI scores (0.64 vs 0.68 ) and BMI were observed between the cohorts (Table 2). Patients in the buttress cohort were more likely to be treated in a 
Table 2 Hospital and patient clinical characteristics before propensity score matching

\begin{tabular}{|c|c|c|c|c|c|}
\hline \multirow[t]{3}{*}{ Baseline variables } & \multirow{2}{*}{\multicolumn{2}{|c|}{$\frac{\text { Non-buttress cohort }}{(N=27,349)}$}} & \multirow{2}{*}{\multicolumn{2}{|c|}{$\frac{\text { Buttress cohort }}{(N=38,231)}$}} & \multirow[t]{3}{*}{ SMD } \\
\hline & & & & & \\
\hline & N/Mean & $\% / \mathrm{SD}$ & N/Mean & $\% / \mathrm{SD}$ & \\
\hline \multicolumn{6}{|l|}{ Patient clinical characteristics } \\
\hline \multicolumn{6}{|l|}{ Body mass index (BMI) } \\
\hline$<40$ & 4982 & $18.2 \%$ & 7105 & $18.6 \%$ & 0.9 \\
\hline $40-45$ & 8727 & $31.9 \%$ & 11,966 & $31.3 \%$ & 1.3 \\
\hline $45-50$ & 5868 & $21.5 \%$ & 8172 & $21.4 \%$ & 0.2 \\
\hline $50-60$ & 5172 & $18.9 \%$ & 7551 & $19.8 \%$ & 2.1 \\
\hline $60-70$ & 1382 & $5.1 \%$ & 1869 & $4.9 \%$ & 0.8 \\
\hline$\geq 70$ & 400 & $1.5 \%$ & 587 & $1.5 \%$ & 0.6 \\
\hline Missing BMI information & 818 & $3.0 \%$ & 981 & $2.6 \%$ & 2.6 \\
\hline \multicolumn{6}{|l|}{ Year of surgery } \\
\hline 2012 & 2250 & $8.2 \%$ & 2838 & $7.4 \%$ & 3 \\
\hline 2013 & 3810 & $13.9 \%$ & 5856 & $15.3 \%$ & 3.9 \\
\hline 2014 & 5574 & $20.4 \%$ & 7153 & $18.7 \%$ & 4.2 \\
\hline 2015 & 6283 & $23.0 \%$ & 8107 & $21.2 \%$ & 4.3 \\
\hline 2016 & 5927 & $21.7 \%$ & 8552 & $22.4 \%$ & 1.7 \\
\hline 2017 & 3505 & $12.8 \%$ & 5725 & $15.0 \%$ & 6.2 \\
\hline Deyo-Charlson comorbidity index score & 0.64 & 0.95 & 0.68 & 1.00 & 4.4 \\
\hline 0 (Reference) & 15,216 & $55.6 \%$ & 20,810 & $54.4 \%$ & 2.4 \\
\hline 1 & 8789 & $32.1 \%$ & 12,179 & $31.9 \%$ & 0.6 \\
\hline $2-3$ & 2846 & $10.4 \%$ & 4380 & $11.5 \%$ & 3.4 \\
\hline $4+$ & 498 & $1.8 \%$ & 862 & $2.3 \%$ & 3.1 \\
\hline \multicolumn{6}{|l|}{ Hospital characteristics } \\
\hline Procedure volume (no. procedures/year) & 840.3 & 448.1 & 743.3 & 383.2 & 23.3 \\
\hline \multicolumn{6}{|l|}{ Hospital type } \\
\hline Teaching & 12,061 & $44.1 \%$ & 17,510 & $45.8 \%$ & 3.4 \\
\hline Non-teaching & 15,288 & $55.9 \%$ & 20,721 & $54.2 \%$ & 3.4 \\
\hline \multicolumn{6}{|l|}{ Hospital location } \\
\hline Urban & 24,627 & $90.0 \%$ & 35,707 & $93.4 \%$ & 12.2 \\
\hline Rural & 2722 & $10.0 \%$ & 2524 & $6.6 \%$ & 12.2 \\
\hline \multicolumn{6}{|l|}{ Hospital size } \\
\hline$<200$ beds & 6715 & $24.6 \%$ & 7206 & $18.8 \%$ & 13.9 \\
\hline $200-499$ beds & 13,574 & $49.6 \%$ & 20,489 & $53.6 \%$ & 7.9 \\
\hline$\geq 500$ beds & 7060 & $25.8 \%$ & 10,536 & $27.6 \%$ & 3.9 \\
\hline
\end{tabular}

$S D$ standard deviation, $S M D$ standardized mean difference

Italics $=$ Significant difference between the study cohorts if SMD $>10$ hospital with lower procedure volume, located in an urban area $(93.4 \%$ vs $90.0 \%$; SMD $=12.2)$ and less likely to be treated in a hospital with $<200$ beds $(18.8 \%$ vs 24.6\%; SMD = 13.9) (Table 2).

\section{Surgical Outcomes}

Before PSM, there was little variation between cohorts in the proportions of in-hospital leaks $(0.4 \%$ vs $0.3 \%$; SMD $=2.4)$, bleeding $(1.3 \%$ vs $2.1 \%$; SMD $=6.5)$, transfusion $(0.6 \%$ vs $0.8 \%$; SMD $=2.5)$, and bleeding/transfusion $(1.5 \%$ vs $2.4 \%$; $\mathrm{SMD}=6.5$; Table 3).

After PSM, there were 24,049 patients in both the buttress and non-buttress cohorts. All patient and hospital characteristics were well balanced after PSM (Fig. 2). Patient characteristics after PSM are presented in Supplemental Table 1.

After accounting for hospital-level clustering in the GEE models, staple line buttressing was associated with a lower 
Table 3 Descriptive outcome characteristics at index hospitalization before propensity score matching

\begin{tabular}{|c|c|c|c|c|c|}
\hline \multirow{2}{*}{$\begin{array}{l}\text { Outcomes } \\
\text { Surgical outcomes }^{\mathrm{a}}\end{array}$} & \multicolumn{2}{|c|}{$\begin{array}{l}\text { Non-buttress } \\
(N=27,349)\end{array}$} & \multicolumn{2}{|c|}{$\begin{array}{l}\text { Buttress } \\
(N=38,231)\end{array}$} & \multirow[t]{2}{*}{ SMD } \\
\hline & N/Mean & $\% / \mathrm{SD}$ & N/Mean & $\% / \mathrm{SD}$ & \\
\hline In-hospital leak & 70 & $0.3 \%$ & 149 & $0.4 \%$ & 2.4 \\
\hline Bleeding/transfusion & 635 & $2.4 \%$ & 554 & $1.5 \%$ & 6.5 \\
\hline Bleeding & 567 & $2.1 \%$ & 478 & $1.3 \%$ & 6.5 \\
\hline Transfusion & 211 & $0.8 \%$ & 218 & $0.6 \%$ & 2.5 \\
\hline \multicolumn{6}{|l|}{ Hospitalization utilization } \\
\hline Index hospitalization length of stay, days & 1.70 & 3.67 & 1.75 & 0.97 & 1.7 \\
\hline $\begin{array}{l}\text { Operation room time during index hospitalization, hours } \\
\text { between } 30 \mathrm{~min} \text { and } 24 \mathrm{~h}(N=23,512 \text { vs. } 32,060)\end{array}$ & 3.09 & 3.26 & 2.85 & 2.01 & 8.7 \\
\hline \multicolumn{6}{|l|}{ Hospitalization costs } \\
\hline Total costs & $\$ 10,712$ & $\$ 5406$ & $\$ 11,477$ & $\$ 4844$ & 14.9 \\
\hline Operation room & $\$ 4040$ & $\$ 2431$ & $\$ 3752$ & $\$ 2148$ & 12.5 \\
\hline Room and board & $\$ 993$ & $\$ 847$ & $\$ 1085$ & $\$ 728$ & 11.6 \\
\hline Supply & $\$ 4134$ & $\$ 3696$ & $\$ 4890$ & $\$ 3072$ & 22.3 \\
\hline
\end{tabular}

$S D$ standard deviation, $S M D$ standardized mean difference

${ }^{\text {a }}$ Patients with events that presented on admission were excluded from the numerator and denominator rate of bleeding $(1.37 \%$ vs $1.80 \% ; p=0.015)$, transfusion $(0.56 \%$ vs $0.77 \% ; p=0.050)$, bleeding/transfusion $(1.57 \%$ vs $2.04 \% ; p=0.019$ ), and a similar rate of in-hospital leaks $(0.28 \%$ vs $0.39 \% ; p=0.160)$, as compared with no buttressing during the index hospitalization (Fig. 3).

\section{Hospital Utilization and Costs}

Before PSM, the average index hospitalization length of stay ( 1.75 vs 1.70 days; $\mathrm{SMD}=1.7)$ and operation room time (2.85 vs 3.09 hours; $\mathrm{SMD}=8.7$ ) were similar between the buttress and non-buttress cohorts (Table 3 ).

The index hospitalization LOS (1.75 vs 1.74 days; $p=$ 0.718 ) and OR time (3.31 vs $3.42 \mathrm{~h} ; p=0.644$ ) were similar between the buttress and non-buttress cohorts (Fig. 4).

Before PSM, the average total $(\$ 11,477$ vs $\$ 10,712$; $\mathrm{SMD}=14.9)$, room and board $(\$ 1085$ vs $\$ 993 ; \mathrm{SMD}=$ $11.6)$, and supply costs ( $\$ 4890$ vs $\$ 4134$; $\mathrm{SMD}=22.3$ ) were significantly higher, while operation room costs ( $\$ 3752$ vs $\$ 4040$; SMD $=12.5$ ) were lower in the buttress cohort (Table 3).

Total health care costs during index hospitalization were higher by $\$ 1215$ among patients in the buttress cohort $(\$ 12,201$ vs 10,$986 ; p<0.001)$. That difference was primarily driven by medical and surgical supply costs, which were higher by $\$ 1046$ in the buttress cohort ( $\$ 5366$ vs $\$ 4320$; $p<0.001)$. OR ( $\$ 4156$ vs $\$ 3983 ; p=0.132)$ and room and board costs ( $\$ 1083$ vs $\$ 1075 ; p=0.793$ ) were similar between the buttress and non-buttress cohorts (Fig. 5).

\section{Discussion}

The study is one of the first real-world studies using a large nationwide US healthcare database to compare clinical and economic outcomes associated with buttress use among LSG patients.

After balancing potential confounders using PSM and accounting for hospital-level clustering in the GEE models, individual bleeding, transfusion, and composite bleeding/ transfusion rates were lower by $0.43,0.21$, and 0.47 percentage points, respectively, among the buttress cohort patients compared with the non-buttress cohort, while total hospitalization costs were higher by $\$ 1215$, driven primarily by supply costs.

Evidence from RCTs and prospective studies evaluating effectiveness of buttress materials have reported that buttressing staple lines reduces bleeding events $[6,7,9,12]$. The study by Zafar et al. using Metabolic and Bariatric Surgery Accreditation and Quality Improvement Program dataset from 2015 evaluated postoperative bleeding among LSG buttress patients in the United States. The rate of postoperative bleeding was $0.80 \%$ for patients without suture over-sewing or buttressing and $0.57 \%$ for those with buttress use. After multivariable analyses, the buttress cohort had a $30 \%$ lower rate of bleeding (odds ratio $=0.70$ ) [10]. In the current study, similar trends were found; a 0.23 percentagepoint reduction in postoperative bleeding was observed among buttress cohort patients compared with those in the non-buttress cohort. A large multi-center study also reported post-operative bleeding rates of $\leq 1.7 \%$ among LSG patients, which are consistent with the current study [19]. 


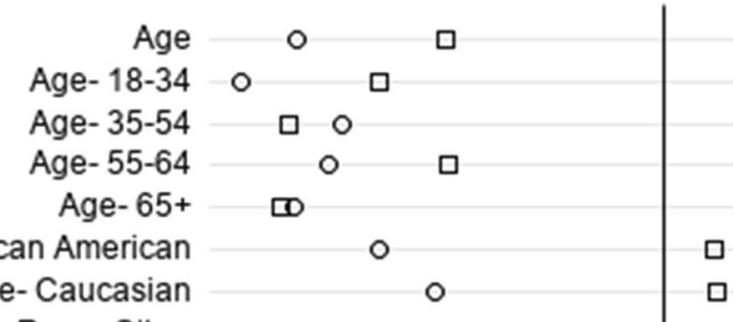

Race- African American

Race- Caucasian

Race- Other

Race- Unknown

Sex-Male

Sex-Female

Marital status- Married

Marital status- Single

Marital status- Other

Region- Northeast

Region- Midwest

Region- South

Region-West

Payer- Managed care and commercial

Payer- Government

Payer- Other

Payer- Indigent and charity

BMI- $<40$

BMI- [40-45)

BMI- [45-50)

BMI- $[50-60)$

BMI- [60-70)

BMI- $>=70$

BMl- Missing Information

Surgery year- 2012

Surgery year- 2013

Surgery year- 2014

Surgery year- 2015

Surgery year- 2016

Surgery year- 2017

Deyo-Charlson comorbidity index $(\mathrm{CCl})$ score

CCl- 0

$\mathrm{CCl}-1$

$\mathrm{CCl}-2-3$

$\mathrm{CCl}-4+$

Procedure volume

Teaching hospital

Non-teaching hospital

Hospital Location- Urban

Hospital Location- Rural

Hospital Size- $<200$ beds

Hospital Size- $200-500$ beds

Hospital Size- $>=500$ beds

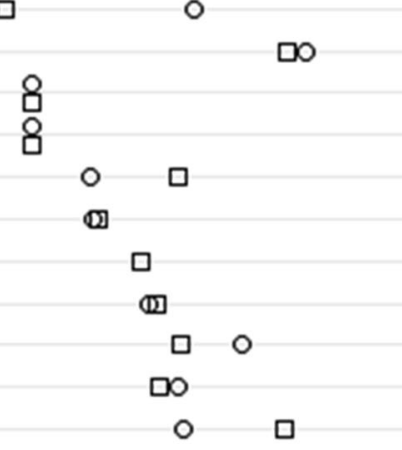
0
$\square \quad 0$
○ $\square$

(1)

OD

8

○ 口

[1]

(1)

○ 口

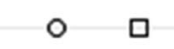

$0 \quad \square$

O 口

O 口

$\begin{array}{ll}0 & 0\end{array}$

$\infty$

ㅇ

0

$\square 0$

○ 口

$\begin{array}{ll}0 & 0 \\ 0 & 0\end{array}$

O 口

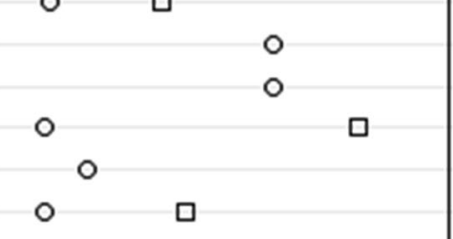

$\square$

$\square$

$\square$

$0 \quad 5$

10

15

20

Standardized Mean Difference

Group $\square$ Pre-PSM o Post-PSM

Fig. 2 Standardized mean differences before and after propensity score matching. Mean standardized difference $\geq 10$ is considered significant; BMI: body mass index; CCI: Charlson comorbidity index; PSM: propensity score matching 


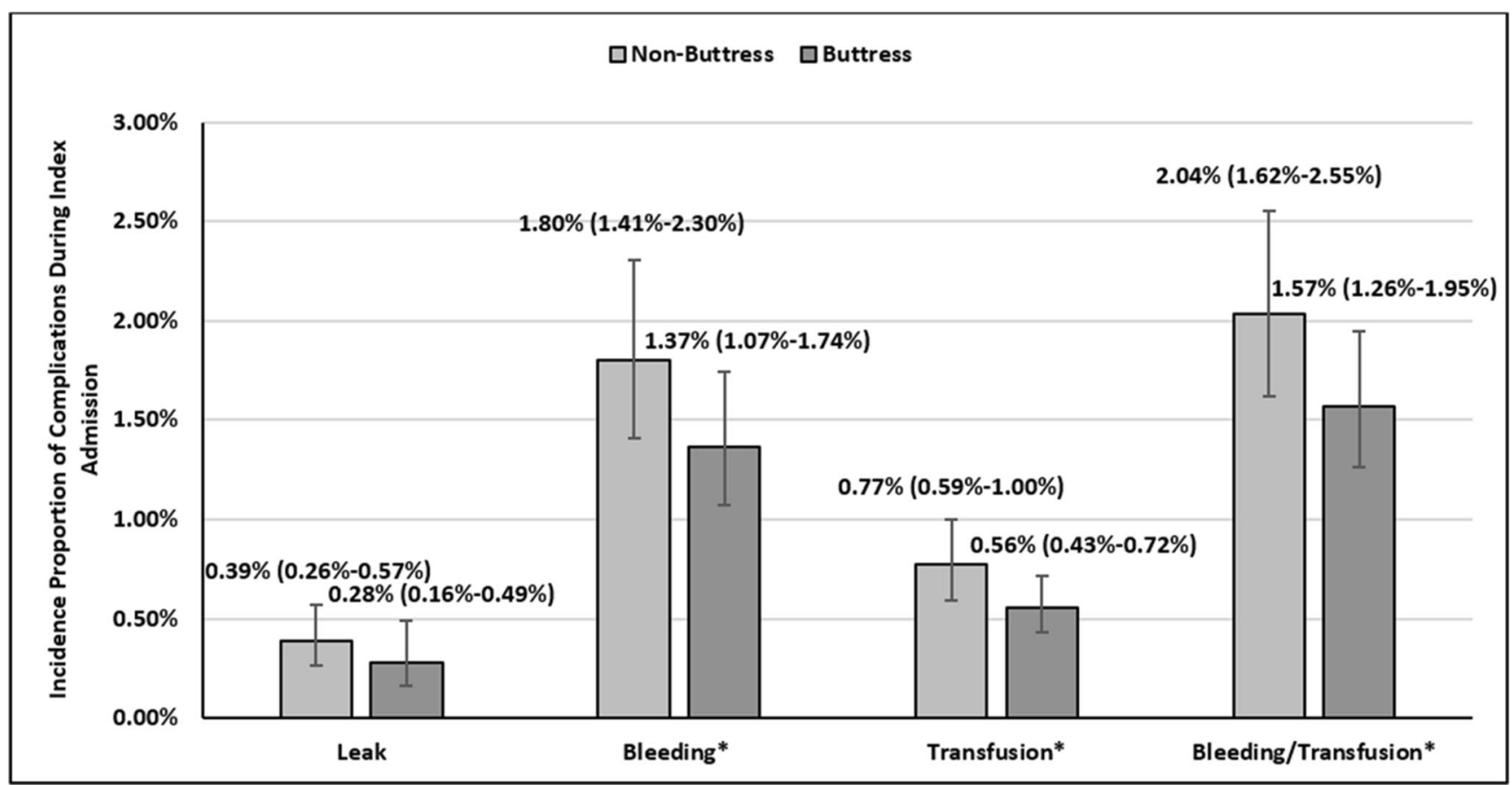

Fig. 3 Surgical outcomes at index hospitalization among sleeve gastrectomy patients with vs. without buttress use. Mean incidence proportion (confidence limits); ${ }^{*} p$ value $<0.05$

There is inconclusive evidence available regarding reduction of leak rates with buttressing staple line among LSG patients. Results of RCTs available to-date could not make such inference owing to inadequate power [7]. Findings from a meta-analysis also remained inconclusive on the outcome among LSG patients [11]. The results of our study did not observe a statistically significant reduction in the rate of inhospital leaks $(0.28 \%$ vs $0.39 \% ; p=0.160)$ among buttress cohort patients compared with non-buttress cohort. Further research into materials that can improve leak rates could be highly beneficial in preventing the possibility of fatal complications such as septic shock ensuing from the complication [20].

\section{$\square$ Non-Buttress $\square$ Buttress}

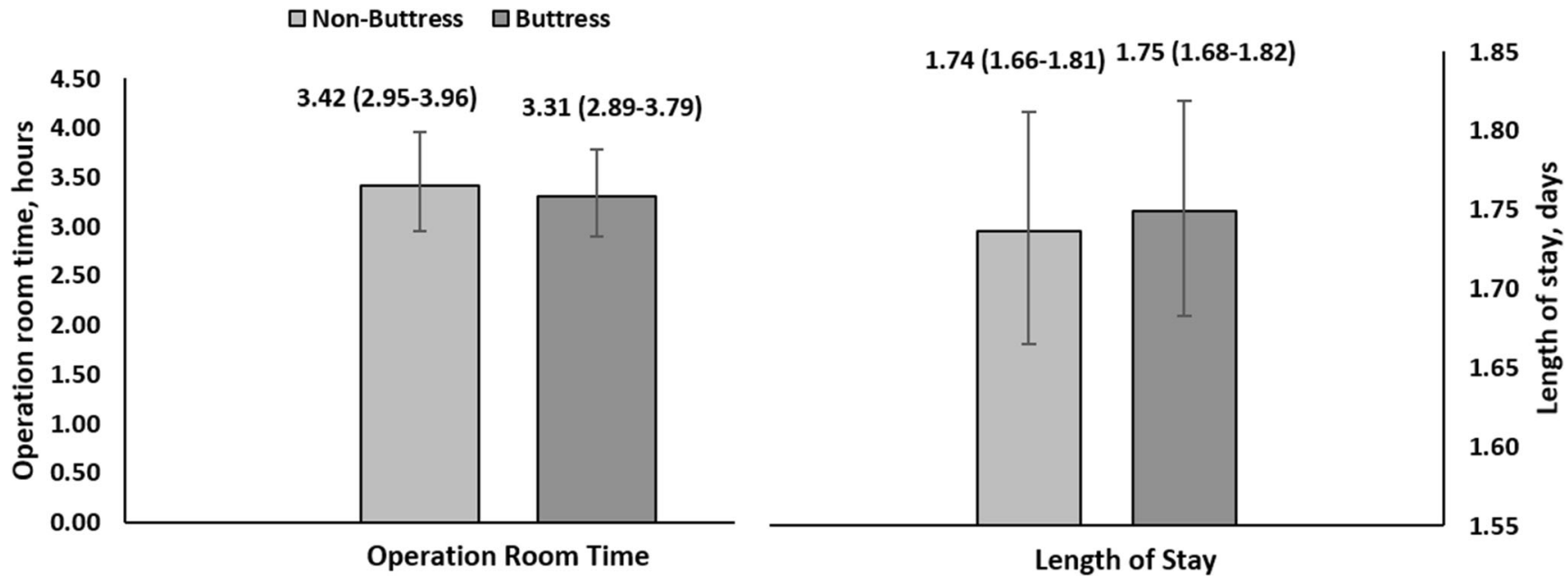

Findings from an RCT showed a reduction in surgical time among patients with buttress use [12]. Though statistically insignificant, the buttress cohort was associated with lower OR time (3.31 vs 3.42 hours). The improvement in surgical time may be the result of lower rates of bleeding complications among patients in the buttress cohort [12].

A study conducted in Europe using absorbable buttress materials reported lower overall costs during the initial hospital stay in the buttress cohort [21]. Our study shows higher total costs among buttress cohort patients $(\$ 12,201$ vs $\$ 10,986 ; p<0.001)$. However, costs within sub-populations of absorbable and nonabsorbable buttress materials were not evaluated in this study. In addition, variations in the costs of procedures and other health

Fig. 4 Index hospitalization utilization among sleeve gastrectomy patients with vs. without buttress use*. Mean time (confidence limits); * $p$ value $>0.05$ 


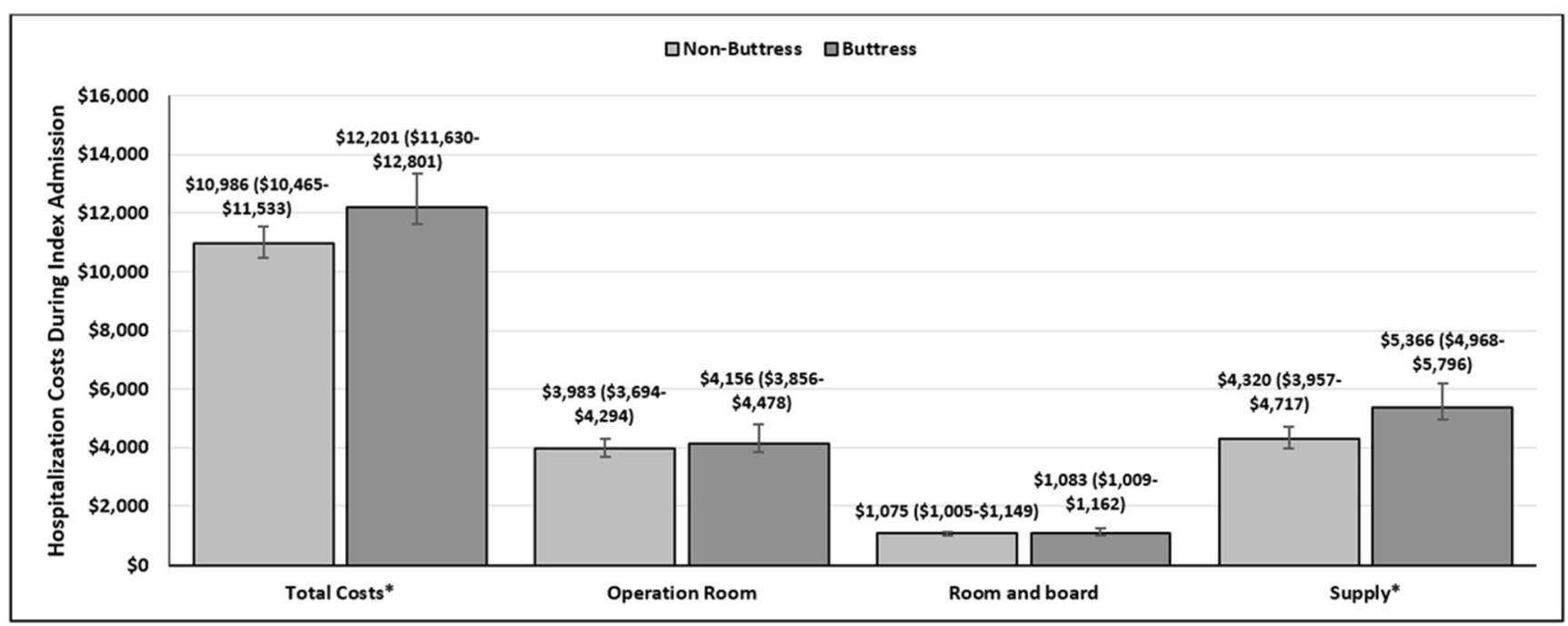

Fig. 5 Hospitalization costs during index hospitalization among patients with and without buttress use. Mean costs (confidence limits); ${ }^{*} p$ value $<0.05$; adjusted to 2017 United States Dollars

care expenses from study conducted in Europe may also have contributed to our conflicting findings. Further research of the cost-beneficial effects of absorbable buttress materials and other buttress materials is warranted.

In addition to the costs of buttress material reflected in medical and surgical supply costs (\$5366 vs \$4320; $p<0.001)$, higher total costs among buttress cohort patients in this study may also be related to unmeasured confounders not accounted for in the study. Providers with more buttress use may also have had a higher usage of other supplies along with buttressing, which may be responsible for the increase in medical and surgical supply costs. Accounting for confounders such as stapler type may elucidate the change in medical and surgical supply costs. Powered staplers are costeffective compared with manual staplers, which incurred nearly $\$ 600$ of additional costs, and their use can help improve cost savings from a policy perspective [22].

\section{Limitations}

This study was subject to limitations. Errors or missing information in the database with respect to study variables and ICD9/10-CM codes can lead to measurement error. The reasons for buttress use and the extent to which buttressing was used by each provider were not capturable in the dataset, and this could introduce selection bias. Residual confounding could exist because of factors such as cartridge and staple height selection [23]. Identification of leak outcomes was limited due to the lack of availability of specific ICD-9/10-CM codes for leak events. Codes used for identifying leak include peritoneal abscess, fistula of intestine (excluding rectum and anus), and other digestive system complications. Specific breakdowns of time in OR and skin-to-skin operation room times were not capturable in the dataset, and OR times should therefore be interpreted accordingly. For a given patient, the PHD longitudinally tracks only hospital encounters occurring within the same hospital and does not include complete information on follow-up visits, and subsequent medical visits of patients to other hospitals are not possible to track. Thus, the majority of information on patient characteristics was ascertained during the index hospitalization, and study outcomes were limited to those within the index hospitalization. In addition, this focus on index hospitalization also precluded capture of outcomes after discharge, including complications such as post-index leaks or bleeding, postoperative mortality, readmissions and reoperations, and costs. Likewise, the thromboprophylaxis practice and anticoagulation history of patients and their influence on surgical outcomes were out of the scope of the study. Further, the dataset did not support capture of certain procedural specifics, such as the use of double vs single-sided buttressing.

Moreover, no statistically significant difference was observed for in-hospital leaks between the buttress and nonbuttress cohorts. However, PSM-adjusted results revealed that the buttress cohort had a higher rate of in-hospital leaks $(0.42 \%$ vs $0.25 \%$, SMD $=2.8$ ) before applying the GEE model, but a lower rate after $(0.28 \%$ vs $0.39 \%)$, which may indicate a correlation between in-hospital leak outcomes and providers.

As this is a non-randomized retrospective, observational study, results require caution in interpretation, only association rather than causation can be inferred. Finally, considering that the study used data from United States, our results may not be generalizable to populations outside the United States.

\section{Conclusion}

Staple line buttressing was associated with an improvement in complication rates for bleeding and transfusion. Total costs 
and supply costs were higher in the buttress cohort, necessitating further research into cost-effective buttressing materials.

Acknowledgments Editorial support was provided by Michael Moriarty of STATinMED Research. Medical Writing support was provided by Michael Kane of STATinMED Research.

Funding This study was funded by Ethicon, Inc.- - a subsidiary of Johnson \& Johnson, Inc.

\section{Compliance with Ethical Standards}

Conflict of Interest Sanjoy Roy and Stephen Johnston are paid employees of Johnson \& Johnson, Inc. Yuexi Wang and Rajesh Mallampati are paid employees of STATinMED Research which is a paid consultant to Ethicon, Inc.

Ethical Statement For this type of study, formal consent is not required.

\section{Consent Statement N/A}

Open Access This article is licensed under a Creative Commons Attribution 4.0 International License, which permits use, sharing, adaptation, distribution and reproduction in any medium or format, as long as you give appropriate credit to the original author(s) and the source, provide a link to the Creative Commons licence, and indicate if changes were made. The images or other third party material in this article are included in the article's Creative Commons licence, unless indicated otherwise in a credit line to the material. If material is not included in the article's Creative Commons licence and your intended use is not permitted by statutory regulation or exceeds the permitted use, you will need to obtain permission directly from the copyright holder. To view a copy of this licence, visit http://creativecommons.org/licenses/by/4.0/.

\section{References}

1. Flegal KM, Carroll MD, Ogden CL, et al. Prevalence and trends in obesity among US adults, 1999-2008. JAMA. 2010;303(3):23541.

2. Mechanick J, Youdim A, Jones D, et al. Clinical practice guidelines for the perioperative nutritional, metabolic, and nonsurgical support of the bariatric surgery patient - 2013 update: cosponsored by American Association of Clinical Endocrinologists, The Obesity Society, and American Society for Metabolic \& Bariatric Surgery. Endocr Pract. 2013;19(2):337-72.

3. Baltasar A, Serra C, Pérez N, et al. Laparoscopic sleeve gastrectomy: A multi-purpose bariatric operation. Obes Surg. 2005;15(8): 1124-8.

4. Rosenthal RJ. International Sleeve Gastrectomy Expert Panel Consensus statement: best practice guidelines based on experience of $>12,000$ cases. Surg Obes Relat Dis. 2012;8(1):8-19.

5. Sarkhosh K, Birch DW, Sharma A, et al. Complications associated with laparoscopic sleeve gastrectomy for morbid obesity: a surgeon's guide. Can J Surg. 2013;56(5):347-52.

6. Consten EC, Gagner M, Pomp A, et al. Decreased bleeding after laparoscopic sleeve gastrectomy with or without duodenal switch for morbid obesity using a stapled buttressed absorbable polymer membrane. Obes Surg. 2004;14(10):1360-6.
7. Dapri G, Cadière GB, Himpens J. Reinforcing the staple line during laparoscopic sleeve gastrectomy: prospective randomized clinical study comparing three different techniques. Obes Surg. 2010;20(4): 462-7.

8. Yo LSF, Consten ECJ, Quarles van Ufford HME, et al. Buttressing of the staple line in gastrointestinal anastomoses: overview of new technology designed to reduce perioperative complications. Dig Surg. 2006;23(5-6):283-91.

9. Stamou KM, Menenakos E, Dardamanis D, et al. Prospective comparative study of the efficacy of staple-line reinforcement in laparoscopic sleeve gastrectomy. Surg Endosc. 2011;25(11):3526-30.

10. Zafar SN, Felton J, Miller K, et al. Staple line treatment and bleeding after laparoscopic sleeve gastrectomy. JSLS. 2018;22(4): e2018.00056.

11. Choi YY, Bae J, Hur KY, et al. Reinforcing the staple line during laparoscopic sleeve gastrectomy: does it have advantages? A metaanalysis. Obes Surg. 2012;22(8):1206-13.

12. Shah SS, Todkar JS, Shah PS. Buttressing the staple line: a randomized comparison between staple-line reinforcement versus no reinforcement during sleeve gastrectomy. Obes Surg. 2014;24(12): 2014-20.

13. Applied Sciences: Real-world evidence to solve real-world problems. Premier website https://www.premierinc.com/solutions/ applied-sciences. Accessed 15 Nov 2019.

14. Premier Healthcare Database: Data That Informs and Performs. Premier website. https://products.premierinc.com/downloads/ PremierHealthcareDatabaseWhitepaper.pdf. Published July 29, 2018. Accessed 26 Nov 2019.

15. Swanson SJ, Meyers BF, Gunnarsson CL, et al. Video-assisted thoracoscopic lobectomy is less costly and morbid than open lobectomy: a retrospective multiinstitutional database analysis. Ann Thorac Surg. 2012;93(4):1027-32.

16. Swanson SJ, Miller DL, McKenna Jr RJ. Comparing robot-assisted thoracic surgical lobectomy with conventional video-assisted thoracic surgical lobectomy and wedge resection: results from a multihospital database. J Thorac Cardiovasc Surg. 2014;147(3):929 37.

17. Austin PC. Balance diagnostics for comparing the distribution of baseline covariates between treatment groups in propensity-score matched samples. Stat Med. 2009;28(25):3083-107. https://doi. org/10.1002/sim.3697.

18. Li Z, Mahendra G. Using "recycled predictions" for computing marginal effects. Lex Jansen website https://www.lexjansen.com/ wuss/2009/hor/HOR-Li.pdf. Accessed 20 Jan 2010.

19. Gero D, Raptis DA, Vleeschouwers W, et al. Defining global benchmarks in bariatric surgery: a retrospective multicenter analysis of minimally invasive roux-en-Y gastric bypass and sleeve gastrectomy. Ann Surg. 2019;270(5):859-67.

20. Serra C, Baltasar A, Andreo L, et al. Treatment of gastric leaks with coated self-expanding stents after sleeve gastrectomy. Obes Surg. 2007;17(7):866-72.

21. Gayrel X, Loureiro M, Skalli EM, et al. Clinical and economic evaluation of absorbable staple line buttressing in sleeve gastrectomy in high-risk patients. Obes Surg. 2016;26(8):1710-6.

22. Roy S, Yoo A, Yadalam S, et al. Comparison of economic and clinical outcomes between patients undergoing laparoscopic bariatric surgery with powered versus manual endoscopic surgical staplers. J Med Econ. 2017;20(4):423-33.

23. Silecchia G, Iossa A. Complications of staple line and anastomoses following laparoscopic bariatric surgery. Ann Gastroenterol. 2018;31(1):56-64. https://doi.org/10.20524/aog.2017.0201.

Publisher's Note Springer Nature remains neutral with regard to jurisdictional claims in published maps and institutional affiliations. 